\title{
Market Potential of Pasteurized Coconut Water in the Philippine Beverage Industry
}

\author{
Hanilyn A. Hidalgo ${ }^{\#}$ \\ ${ }^{\#}$ Department of Agribusiness and Entrepreneurship, Central Bicol State University of Agriculture, Pili, Camarines Sur, Philippines \\ E-mail: hanilyn77@gmail.com
}

\begin{abstract}
Trends in health and well-being are taking the lead in the beverage consumption movement. The waning attractiveness of carbonated beverage may be attributed to the negative impression of the sugar content linking it to health problems. Studies show that coconut water is found to be as effective as a sports drink for rehydration. However, while coconut water may be an old commodity which is usually consumed as fresh, pasteurized coconut water (PCW) becomes a new entrant in the Philippine beverage industry. As a new player, penetrating the market of the giant beverage manufacturers seem to be risky and challenging. The study aimed to determine the market potential of bottled pasteurized coconut water and to identify product positioning opportunity in the beverage market. The study employed random consumption survey and product test. Van Westerndorp price sensitivity meter was used in determining the ideal price for PCW. The properties of PCW against the respondents' top beverage were used as bases for product positioning. The study revealed that $\mathrm{PCW}$ is widely accepted by the general consumers and the target market using common beverage attributes. PCW is positioned as a functional health drink that could serve as a substitute beverage to bottled water and sports drink. The natural and functional appeal of PCW may serve as its product differentiation tool in penetrating the beverage market and attracting consumers with active and healthy lifestyle. With high market acceptability, there is a huge potential for PCW to infiltrate the Philippine beverage industry.
\end{abstract}

Keywords - pasteurized coco water; market potential; natural beverage; Philippine beverage industry

\section{INTRODUCTION}

The shift in consumer lifestyles and culture has changed the market's choices for beverages. Such changes pushed manufacturers to offer various options in ingredients like functional nutritional ingredients. Niche markets for beverages emerged and expanded innovations in beverage product catered to customers with specific health problems [1].

The global consumption trend in beverage industry that occurred in 2007 and 2008 would prove that innovative drinks with greater functionality posted higher growth rates [2]. In 2014, the Datamonitor Consumer Global Survey revealed that 61 percent of US consumers use food and drinks to boost their health [3].

Though soft drink consumption is continuously rising in many countries, bottled water has still the highest consumption record in the United States. The waning attractiveness of carbonated beverage may be attributed to the negative impression of the sugar content in soft drinks linking it to obesity and diabetes [4]. The level of consumption of carbonated drinks is even expected to decline by $3.9 \%$ from 2015-1019. In 2014, it already declined by $1 \%$ to 12.76 billion gallons according to Beverage Marketing Corporation. Accordingly, that figure is so far the lowest per capita consumption of the industry for almost three decades [3].

The popularity of diet beverages is an indication that even soft drink manufacturers have accepted the reality that consumers have shifted to a healthier food lifestyle. In fact, they already changed the composition of their beverages to "gluten-free" drinks.

While trends in health and well-being are taking the lead in consumption movement, still, the price has become a significant factor in decision-making [2]. From among the non-alcoholic beverages, isotonic or sports drinks are the most price and expenditure elastic followed by soft drinks [5].

Interestingly, coconut water offers the same isotonic advantage in a natural form. Thus, it provided an opportunity for beverage companies to create a new category in the beverage market. Minerals such as potassium, sodium, magnesium, calcium, phosphorus, and chloride are present in coconut water. This makes it an isotonic drink due to the electrolytes found in the beverage [6]. Coconut water contains a high amount of electrolytes relative to regular sports drinks. That is why it is considered 
as a natural isotonic sports beverage [7]. Coco water is found to be as effective as a sports drink for rehydration. With good tolerance and acceptability, the former can substitute the latter provided it is accessible to the intended users [8].

The health conscious market's interest in functional foods such as longevity foods, nutritional foods, super foods, pharmaceutical foods, phyto foods and therapeutic foods provide a bright prospect for coco water to penetrate the beverage industry. Developing countries could capitalize this neutral drink since this is less expensive and does not pose any side effects. It is found to be an accessible medicine source of various diseases such as diabetes, coronary vascular diseases, in the developing countries [9].

However, while coco water may be an old commodity which is usually consumed as fresh, bottled coco water in a pasteurized form becomes a new entrant in the beverage industry. As a new player, penetrating the market of the giant beverage manufacturers seem to be risky and challenging. Without a careful understanding of the market dynamics in the beverage industry, the likelihood of moving the product into the mainstream setting could jeopardize the prospects of coco water as a functional natural drink. The guarantee of a value-added coconut industry could leave the farmers into false hopes if a market assessment were not undertaken. Hence, there is a need to explore if there is really a product-market fit for coco water in the Philippine beverage market.

The study aimed to: 1) characterize the target markets of pasteurized coco water; 2) estimate the demand potential of coco water; 3) determine the market price expectation for pasteurized coco water; 4) assess the market response of pasteurized coco water, and 5) develop product positioning strategy for pasteurized coco water

The conceptual framework of the study is anchored on three determinants of market potential in a competitive market, the three Ps: Preference, Price and Product Features.

\section{A. Market Preference}

Preference is one of the bases in segmenting consumer markets. Customer responses to products vary depending on geographic, demographic, psychographic and behavioral characteristics of a buyer. (Kotler, 1994) Collectively, this translates to a bigger phenomenon such as fad, fashion, and trend. The choice of consumers signals the changing nature of needs and wants. Coco water is a response to the increasing trend in a healthy lifestyle in the food sector. The beverage consumption behavior of the target market is a significant input in determining the market potential of coco water. The preference was estimated using the chain ratio method of computing demand potential.

\section{B. Price}

Price is a major determinant of demand more particularly in a monopolistic competitive market. This determines the value of the benefit the product provides to the consumer. The price elasticity of a product may significantly affect the demand such as the case of isotonic. ${ }^{5}$ In this paper, coco water was subjected to price analysis using price sensitivity meter to address the issue of consumer price expectations and threshold perceptions [10].

\section{Product Features}

The physical and sensory attributes are contributory factors in deriving the benefit of a product. These benefits, as a result, could lead to product-market fit. The distinctiveness of the features will serve as a competing factor in the industry. The study used a product test to determine the effectiveness of the sample pasteurized coco water. Four attributes of beverage were used in determining the market acceptability of coco water: 1) health benefits, 2) taste, 3) appearance, and 4) size.

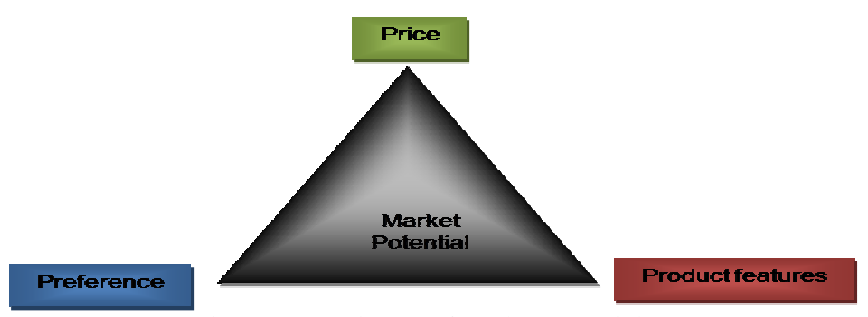

Fig. 1 Determinants of market potential

\section{MATERIAL AND METHOD}

\section{A. Research Design}

The study is a descriptive type of research which focused on understanding the market to develop a detailed marketing program for coco water as a village-level enterprise. It utilized market research tools such as a partial of the Usage, Attitude, and Image (UAI) study, product prototype test, and price sensitivity analysis. These tools collectively paved the way in understanding the perspective of the consumers.

\section{B. Sampling}

The main respondents of this research were the beverage consumers. The UAI, prototype test, and price sensitivity analysis were used in the survey method. There were two sets of respondents for the survey: the general market of beverage and the target market of existing coco water brands. The general market refers to the consumers of a wide range of beverages while the target market refers to the intended consumers of coco water. The result of the general market respondents was used to analyze consumption behavior of beverage in general. Meanwhile, the product prototype test and price sensitivity were used to the target market respondents.

The 300 consumer-respondents were clustered into three key cities: Naga City, Metro Manila, and Cebu City. These respondents were selected using a random sampling technique with 100 each cluster.

For the target market-respondents in the prototype test, random sampling was also used to the three types of 311 consumers with an active lifestyle: sports enthusiasts, health-conscious and students. They were spotted in events and locations where their active routines occur such as triathlon event, gyms, offices, restaurants, and schools. The prototype testing was, however, limited to Naga City and Pili due to the shelf-life factor of the product. 


\section{Data Collection and Analysis}

The study employed three methods of data gathering: survey method, key informant interviews, and focus group discussions (FGD). The survey method was used to determine the UAI of beverage and consumer feedback of the prototype. Pre-tested questionnaires were used in the survey. The prototype test questionnaire seeks to solicit feedbacks about the product's attributes which include price, brand and potential demand. Key informant interviews were adopted to determine from the supply side through the farmers and the demand side through the dealers the financial feasibility and success factors of the coco water as an emerging industry. FGD was used to gather the industry experts and stakeholders from the coco water industry. This paper utilized descriptive statistics, chain ratio method, diagnostic product positioning mapping and price sensitivity meter [10] in estimating and analyzing the raw data.

\section{RESULTS AND DISCUSSION}

The beverage industry as a whole can be characterized as a matured industry. Hence, other novelty drinks were introduced to keep the manufacturers from their continued existence. For instance, when consumption of healthy foods became a trend, new health drinks were immediately launched by the beverage companies. Soft drink companies are now moving into non-carbonated drinks which are perceived healthier drinks.

Coco water is an old commodity yet a new entrant in the beverage industry. Categorically, it belongs to the natural foods industry but competes head-to-head with carbonated and sports drinks. With very few players, this sector is just a small fraction of the entire industry. In 2011, the Philippine Coconut Authority (PCA) reported an increase of 315 percent coconut water exports from 1.80 million liters in 2010 to 715 million liters with the US as the biggest market [11].

Unlike the processed coco water commercially sold in the market, pasteurized coco water (PCW) is a minimally processed beverage that comes from the water of a matured coconut which is usually 10 to 12 months old. Mature coconut water was found to have higher contents of inorganic ions such as calcium, magnesium, phosphorus, potassium, and sodium than the young coconut water [12]. Pasteurization was done for 15 minutes, thus, retaining most of its original attributes. Hence, the pasteurized coco water is comparable to the fresh coco water. Pasteurized coco water can last only up to 8 days under chilled condition. Pasteurization had no significant effect on the physicochemical properties of the product. The product has the total fat of $0 \mathrm{~g}$, total carbohydrates of 3-4 g, and protein of $<1 \mathrm{~g}$, and minerals such as sodium (30-35 mg), potassium (180-270 mg), and calcium (36 mg), and a caloric content of $15 \mathrm{cal} / 120 \mathrm{~mL}$ serving.

\section{A. Market Characterization}

Given the natural properties of coco water, popular brands of coco water revealed that the current markets of their products are those who have active and/or healthy lifestyle. Based on the data collected from the survey, FGDs, key informant interviews and secondary data, there are three segments to which marketing of pasteurized coco water may be considered. The segmentation used in this study is the psychographic segment wherein the preferences, perceptions, lifestyle, interests, and values were considered to align with the personality of the coco water. The positive result of the 'willingness to buy' factor of these groups upholds the stance of the segmentation-targeting process.

The first two market segments would look for a functional drink that would either give them a replenished energy effect or an added nutritional benefit to their diets. On the other hand, the last market segment's principal aim is to consume the beverage for refreshment.

1) Health-Conscious Segment: The first type of market segment belongs to a huge consumer movement called LOHAS. LOHAS stands for Lifestyle of Health and Sustainability. They are consumers interested in goods and services focused on health, the environment, social justice and sustainable living. LOHAS advocates are well-off, welleducated, health-conscious and socially and environmentally aware [13]. This group has an ardent need for nutritious drinks due to health reasons and does not actually need marketing persuasions in order to buy. They will do the product hunting themselves. Since their beliefs for goods and services are much stronger than its price, coco water then becomes, generally, an inelastic product for this group.

The research on the Philippines Food and Drinks Market: Emerging Opportunities revealed that this segment is dominant particularly to the young, affluent population. The survey of Philips Index Health and Living revealed that 54 percent of the Filipino population rated themselves as conscious about their health and well-being [14]. These are people who pay more attention to their food intake that will contribute towards a healthy being.

2) Athletes and Sports Enthusiasts Segment: Athletes and sports enthusiasts have the most active lifestyle. According to Chris Schmidt, a consumer health analyst of Euromonitor International, this particular segment can be further categorized into two sub-segments: the fitness fanatics and the casual users. The fitness fanatics consist of the strength athletes, endurance athletes, professional athletes, bodybuilders, and trainers. They tend to be relatively well-informed of the latest sports nutrition supplements and food and sometimes are selective of the products they consume. The casual users are the weekend warriors, amateur athletes, and persons who play sports/run/go to the gym to maintain a moderate level of fitness [15]. A big portion of this group capitalizes on sports nutrition products as healthier snack replacements without specific fitness goal being followed. The burgeoning number of gyms and fitness centers in the country is an indication that this segment is substantially growing.

3) Students and Young Generation Segment: The result of the series of FGDs with the students from different levels (primary to tertiary levels) proved that PCW has a strong positive response in this segment. As young as grade six, they were already selective of the beverage they drink at school. In fact, they believe that a certain processed tea drink is a healthy beverage. In all levels, for as long as the price of the product is still within their budget, they welcome the opportunity of including PCW in their choice 
of beverage. The product is deemed elastic for this particular segment. The presence of buko juice in plastic cups in school canteens and its vicinity is a good indicator that this young generation is a good prospect for PCW.

The basis for market selection was built from the functional benefits of the coco water and the desires of the consumers. The findings of Yong et al. (2009) in the study on The Chemical Composition and Biological Properties of Coconut Water [12] uncovered various applications of coco water which indicate huge potentials in improving human health.

\section{B. Market Potential}

The product test conducted to three segments of the market with an active lifestyle such as the athletes/ sports enthusiasts, health-conscious individuals and students showed a high acceptability rating. After tasting the 330-ml pasteurized coco water, almost 98 percent are willing to substitute coco water from their preferred beverage.

In a survey conducted by the Food and Nutrition Research Institute (FNRI) among households in the country, about 76.6 percent revealed that nutrition facts greatly influence consumers in buying a product. Further, in the market survey, about 36 percent consider health benefits as their reason for buying a beverage. In the product test administered to college students both in public and private universities, 97 percent showed a willingness to buy and substitute coco water to their preferred beverages.

Using the chain ratio method, the estimated the demand potential of a village-level facility of coco water in the pilot site in Pili, Camarines Sur is valued at P15,573,416 (US\$331,349). With an average of twenty five-peso (US\$0.53) market price per bottle of healthy beverage, the quantity of demand is estimated at 622,937 bottles annually. These values were computed using the variables and actual values in Table 1.

TABLE I

VARIABLES AND VALUES USED IN ESTIMATING MARKET Potential OF HEALTHY BEVERAGE IN A VilLAGE-LEVEL

\begin{tabular}{|l|c|c|}
\hline \multicolumn{1}{|c|}{ Variables } & Values & $\begin{array}{c}\text { Source of } \\
\text { data }\end{array}$ \\
\hline $\begin{array}{l}\text { Population } \\
\text { Naga City } \\
\text { Pili, Camarines Sur }\end{array}$ & $\begin{array}{c}172,100 \\
82,234\end{array}$ & $\begin{array}{c}\text { Metro Naga } \\
\text { Development } \\
\text { Council report }\end{array}$ \\
\hline $\begin{array}{l}\text { Health conscious beverage } \\
\text { market }\end{array}$ & $36 \%$ & Primary data \\
\hline Per capita income in Bicol & 38,569 & $\begin{array}{c}\text { Philippine } \\
\text { Statistics } \\
\text { Authority }\end{array}$ \\
\hline $\begin{array}{l}\text { Average percentage of food } \\
\text { expenditure }\end{array}$ & $49 \%$ & $\begin{array}{c}\text { Philippine } \\
\text { Statistics } \\
\text { Authority }\end{array}$ \\
\hline $\begin{array}{l}\text { Average percentage of food } \\
\text { expenditure that is spent on } \\
\text { non-alcoholic beverages }\end{array}$ & $0.9 \%$ & $\begin{array}{c}\text { Philippine } \\
\text { Statistics } \\
\text { Muthority }\end{array}$ \\
\hline $\begin{array}{l}\text { Estimated } \\
\text { Potential }\end{array}$ & $\mathbf{P 1 5 , 5 7 3 , 4 1 6}$ & \\
\hline & $\mathbf{o r}$ & \\
\hline
\end{tabular}

\section{Market Price Expectation}

A perceived value pricing approach was used by the respondents in determining the price at which they are willing to buy the product. With the $330-\mathrm{ml}$ size using polyethylene bottle, forty percent of the respondents are willing to buy for PhP10 (US\$0.21) while about thirty-three percent are willing to buy for PhP15 (US\$0.32) per bottle. This result may be attributed to the respondents' comparative price analysis with their preferred beverage. A typical $330-\mathrm{ml}$ bottled water is regularly priced in retail stores at PhP10 (US\$0.21) while a 500-ml content ranges from $\mathrm{PhP8}$ (US\$0.17) to PhP16 (US\$0.34). Entrants may find difficulty in competing with bottled water unless there is a unique proposition that will brush off inconsistencies and product failures of the leading brands.

A separate survey was conducted to 238 respondents who have participated in the product taste tests of the project. Using van Westendorp price sensitivity meter model, the ideal price for coco water resulted to PhP15 (US\$0.34). It is the point at which the number of respondents who reject the product as too expensive approximately equals the number who reject it for being too cheap. Using the same model, the range of acceptable prices was estimated to be between PhP12 (US0.26) and PhP24 (US\$0.51). This means that the price should not fall below PhP12 nor go beyond $\mathrm{PhP} 24$. If coco water is priced below $\mathrm{PhP} 12$, consumers will start to feel that it is too cheap so that they will not buy it anymore. In the same manner, if the coco water will be priced above $\mathrm{PhP} 24$, consumers will feel that the product is too expensive so that they would actually not consider buying any more.

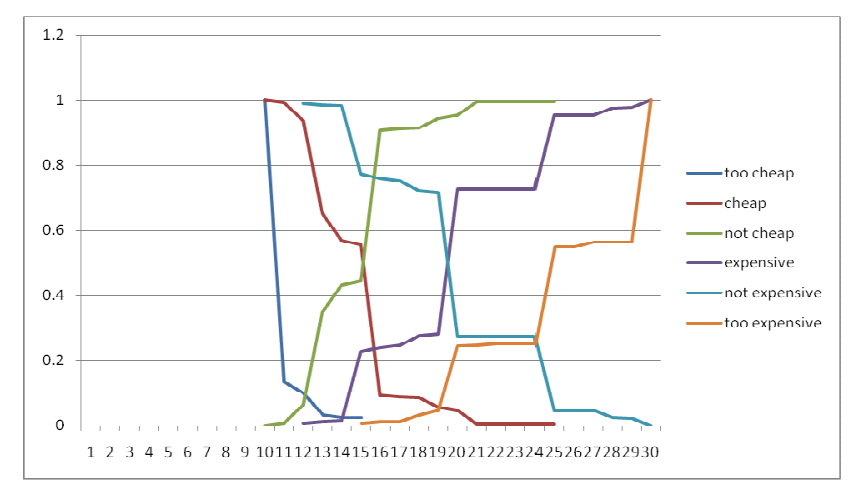

Fig. 2 Price sensitivity survey of pasteurized coco water, $1^{\text {st }}$ quarter, 2016

Hence, in cases where the product is pressured into increasing or decreasing its price for reasons that may affect the profitability of the enterprise, the limit should be within the range of acceptable prices. Otherwise, the enterprise may experience consequences of consumer reversal of buying decisions.

\section{Market Acceptability of Pasteurized Coconut Water}

Four attributes of beverage were used in determining the market acceptability of coco water: 1) health benefits, 2) taste, 3) appearance, and 4) size. All attributes were rated 'very good' by the target market. With health benefit as the top attribute, there is an assumed belief that coco water truly exhibits beneficial effects that customers find valuable. The target markets were also impressed by the natural taste of the bottled coco water as manifested by a 'very good' rating 
followed by the health benefit attribute. This further implies that their level of expectation for its taste was met. The physical properties such as appearance/color and size were also highly acceptable. In addition, the table shown below further validates coco water's contention to sell to athletes, health buffs and students as indicated by the ratings provided by each market segment.

TABLE II

RESPONDENTS’ EVALUATION OF COCONUT WATER ATtRIBUTES

\begin{tabular}{|l|l|l|l|l|l|l|}
\hline Attributes & Athletes/sports enthusiasts & $\begin{array}{l}\text { Health } \\
\text { Buffs }\end{array}$ & Students & AWM & VI & R \\
\hline Health Benefits & 3.85 & 3.83 & 3.76 & $\mathbf{3 . 8 2}$ & VG & 1 \\
\hline Taste & 3.39 & 3.48 & 3.34 & $\mathbf{3 . 4 0}$ & VG & 2 \\
\hline Appearance & 3.47 & 3.40 & 3.17 & $\mathbf{3 . 3 5}$ & VG & 3.5 \\
\hline Size & 3.39 & 3.29 & 3.36 & $\mathbf{3 . 3 5}$ & VG & 3.5 \\
\hline AWM & $\mathbf{3 . 5 2}$ & $\mathbf{3 . 5 0}$ & $\mathbf{3 . 4 1}$ & $\mathbf{3 . 4 8}$ & VG & \\
\hline VI & VG & VG & VG & VG & & \\
\hline R & 1 & 2 & 3 & & & \\
\hline
\end{tabular}

Legend:

\section{Mean Range \\ $3.26-4.00$ \\ 2.51-3.25 \\ $176-2.50$ \\ $1.00-1.75$}

Verbal Interpretation
Very Good (VG)
Good (G)
Fair (F)
Poor (P)

After drinking a sample of coco water, the 311 respondents were asked to cite an attribute they like best about the product. About 94 per cent of the respondents imparted four product features of the coco water that have positively created an impact to their level of expectations. First, the natural taste of real coco water remained to be untainted. More than half of these respondents were impressed with the natural taste of the bottled coco water. Second, healthy alternative drink image of the product was validated. They were surprised to learn that the coco water lasted for a week even without preservatives. Third, the refreshing effect of the product was comparable with the sports drink and carbonated drinks that they have tested. The excitement was noticed when they learned that coco water could be positioned as an alternative to the leading sports drink in the country. And last, a small percentage (five percent) of these respondents finds the size or volume sufficient enough for consumption. This may be attributed, though, to the affordability factor of the size considering the product benefits it offers.

However, they expected a taste that is similar to young coconut water locally known as buko juice. Apparently, the young coconut juice is sweeter than mature coconut water due to higher sugar content (Yong et. al, 2009). These respondents admitted that they are used to drinking the young coconut water. Hence, they presumed that the bottled coco water is a bottled young coconut juice. It implies that an informative marketing campaign must be integrated into the promotional strategy of coconut water.

\section{E. Product Positioning}

Pasteurized coco water's (PCW) elements of uniqueness or differentiation were factored in during the series of FGDs participated by consumers with an active lifestyle. Beverage consumers were asked of the attributes that are important to them and were further asked to rate the level of difference or uniqueness from their perceived closest competitor of PCW. Bottled water turned out to be the nearest substitute beverage for PCW. Hence, the attribute differentiated importance rating was used relative to bottled water.

During the FGD series, only three attributes appeared to be common among the beverage consumer groups (sports enthusiast, health-conscious market, and students). These are price, taste and health benefits. The other attributes were mentioned particularly by the young consumer groups aging from 9 to 20 years of age. This, therefore, recognizes the fact that different target markets may have different preferences. For young market who are product imageconscious, the physical appeal and popularity of a beverage are deemed important to them.

The result of the rating is illustrated in the diagnostic positioning matrix below. The key differentiating features of PCW vis-à-vis with bottled water are expiration, taste, price and health benefits. Though expiration attribute is negatively differentiated with bottled water (since PCW's shelf life is only up to 8 days), PCW can capitalize this feature which would associate it to freshness and enhance two other product attributes such as taste and health benefits.

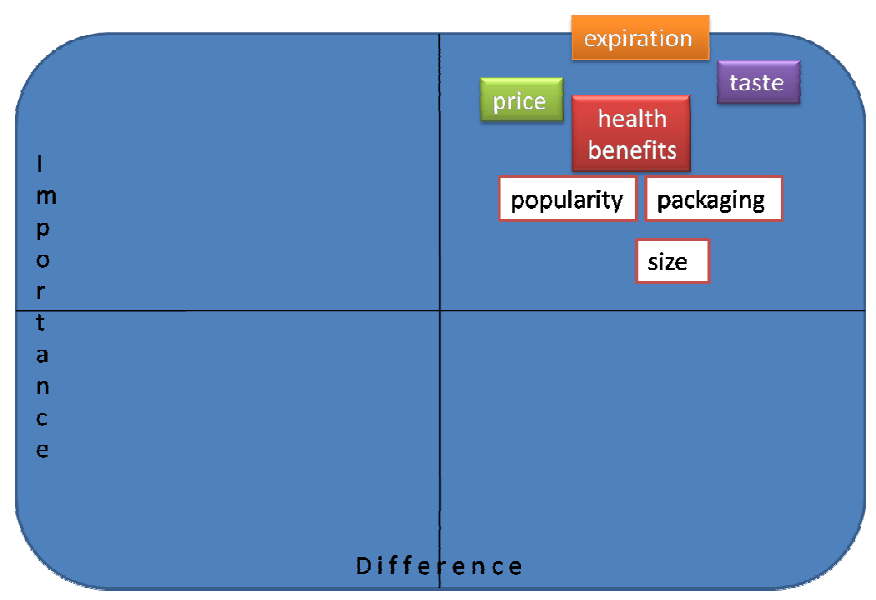

Fig. 3 Diagnostic positioning matrix of pasteurized coco water against bottled water 
After key features were identified, a positioning statement for PCW is hereby suggested. For people with an active lifestyle who need healthy refreshment, Pasteurized Coco Water is an energizing drink taken from the water of a mature coconut fruit that offers a pure, fresh and natural taste. Unlike bottled water, Pasteurized Coco Water provides organic sources of potassium, sodium, chloride, and carbohydrate which immediately revitalize the human body.

The unique selling proposition (USP) of the product will center on substituting the top beverage (water). It is proposed to be marketed as a drink that is more than water.

\section{CONCLUSION}

PCW's entry in the beverage industry is a timely response to the growing health awareness of Filipinos. Such growth is brought by wellness and fitness trends popularized by gyms, spa, and activities like yoga, zumba, fun run and sports. Consumption demand for nutritious and healthy drinks is expected to continue to expand in conjunction with the "growing health consciousness and the reputation of carbonates as unhealthy" [17].

However, PCW will be infiltrating the giants' world where competition is run by 'economies of scale' and heavy advertisements. PCW's point of entry is through a villagelevel production where, relatively, production is low. The perceived elastic nature of the product should signal that the price should be within the acceptable range of the market.

The result of the product test proved that there was a positive response and wide acceptance of PCW in the three market segments identified. Such is an indication that consumers are continuously looking for healthier alternatives to carbonates and commercial beverages. The presence of natural electrolytes in the product provided them more reason to like PCW and probably choose it over other beverages. The natural and functional appeal of PCW will serve as its product differentiation tool in penetrating the beverage market and attracting consumers with active and healthy lifestyle.

Indeed, given the response of the market, there is a huge potential for PCW to enter the Philippine beverage industry. Since 2004, coco water has already successfully penetrated the US and European market. In 2010, the New Nutrition Business had acclaimed coco water as the "fastest growing new category" in the industry with retail sales above $\$ 450$ million worldwide [18]. PCW should, then, be positioned in such a way that the natural edge of the product would be highlighted.

\section{ACKNOWLEDGMENT}

The author would like to thank the Department of Agriculture-Philippine Rural Development Project for funding the research, the Philippine Center for Postharvest Development and Mechanization for developing the villagelevel coconut water facility and the Central Bicol State University of Agriculture for the administrative and logistic support.

\section{REFERENCES}

[1] Chambers, Edgar. "Beverages: A requirement for life and an opportunity to impact the way we live it," Beverages 2015, 1, 1-2; doi:10.3390/beverages1010001

[2] Neves, Marcos Fava et.al. "Market drivers of the global beverage consumption in 2010: Opportunities for a new positioning to the juice category," Paper presented at the IFAMA 2011 Forum and Symposium on May 21, 2011.

[3] Moloughney, Sean. "Healthy beverages tap into emerging market trends. Nutraceuticals World," July 1, 2015. Available at http://www.nutraceuticalsworld.com/issues/2015-

07/view_features/healthy-beverages-tap-into-emerging-markettrends.

[4] Zheng, Miaobing et.al. "Substitution of sugar-sweetened beverages with other beverage alternatives: A review of long-term health outcomes," Journal of the Academy of Nutrition and Diatetics. Volume 115, Number 5, May 2015.

[5] Dharmasena, Senarath and Capps, Oral Jr. “ Demand interrelationships of at-home nonalcoholic beverage consumption in the United States,"Paper presented at the Agricultural \& Applied Economics Association's 2009 AAEA \& ACCI Joint Annual Meeting, Milwaukee, Wisconsin, July 26-29, 2009.

[6] Jayasundera, Mithila and Dharmasena, Anil. "Preservation of tender coconut water of Sri Lankan tall coconut variety," Annals. Food Science and Technology. Volume 15, Issue1, 2014.

[7] Majeed, Muhammed. "Cococin:Tropic thunder," Asia Pacific Food Industry, May 2009.

[8] Idarraga, Alexandra Perez and Vargas, Luis Fernando Aragon. " Post-exercise rehydration with coconut water. Is it as effective as a sports drink? "Revista MHSalud (ISSN: 1659-097X) Vol. 1. No. 8. January-July, 2011.

[9] Thejazvi, Shubhashree. "Therapeutic and nutritional values of Narikelodaka (Tender Coconut Water) - A review," Research Journal of Pharmacognosy and Phytochemistry. 6(4): October-December, 2014, 195-201

[10] Eduardo, Roberto. Applied Marketing Research for Data-Based Marketing Decisions. Ateneo de Manila University Press. ISBN 971113-064-5. pp. 18-23. 1987

[11] Forbes, Euclides. "Outlook for the coconut industry," Paper presented at the Bangko Sentral ng Pilipinas on March 6, 2013.

[12] Yong, Jean W.H. et.al. " The chemical composition and biological properties of coconut (Cocos nucifera L.) water," Molecules 2009, 14, 5144-5164.

[13] Derryberry, Jennifer. "Are you living LOHAS? "Experience Life Magazine. April 2005. Available at https://experiencelife.com/article/are-you-living-lohas/

[14] MacFadden, Declan. "Emerging taste trends in PH," Philippine Daily Inquirer. June 6, 2011.

[15] "Winning in the Sports Nutrition Segment," Natural Products Insider. $\begin{array}{llll}\text { May } & 22, & 2014 . & \text { Available at }\end{array}$ http://www.naturalproductsinsider.com/articles/2014/05/winning-inthe-sports-nutrition-segment.aspx

[16] Kalman, Douglas et.al. "Comparison of coconut water and a carbohydrate-electrolyte sport drink on measures of hydration and physical performance in exercise-trained men," Journal of the International Society of Sports Nutrition 2012, 9:1

[17] "Market research in Philippines: Country reports," Euromonitor International. Available at http://www.euromonitor.com/philippines?id=2\&sortby=5\&pagesizes $=50$.

[18] "Coconut water: innovation and natural health benefits drive a new category," New Nutrition Business. 2010

[19] Kotler, Philip et. al. Marketing Management An Asian Perspective. Prentice Hall Inc. 1994. 